\title{
STATE LICENSURE BOARDS AND REQUIREMENTS
}

Here is some basic information regarding licensure requirements by state as of 2010. For complete information, please visit the state licensing board website.

\author{
ALABAMA \\ Alabama Board of Examiners in Counseling \\ 950 22nd St. North, Suite 765 \\ Birmingham, AL 35203 \\ (800) 822-3307 \\ (205) 458-8716 \\ (205) 458-8718 (fax) \\ Walter H. Cox, Ex. Officer: Walter.Cox@abec.alabama.gov \\ www.abec.state.al.us
}

Title of License: Licensed Professional Counselor (LPC)

Associate Licensed Counselor (ALC)

Note: ALCs work under LPCs to attain hours for licensure.

Educational Requirements: Master's degree in counseling from a CACREP- or CORE-accredited program (or its equivalent) defined as 48 semester hours or 72 quarter hours.

Experiential Requirements: ALC is given when master's is verified. No experiential requirements. LPC: 3,000 hours of supervised experience in professional counseling with board approved supervision. An applicant may subtract 1,000 hours of the required professional experience for every 15 graduate semester hours (or 22.5 quarter hours) obtained beyond the master's degree from a regionally accredited college or university, provided that such hours are clearly related to the field of professional counseling. This formula can be used for up to 2,000 hours. 
(Note: In the ACA book on state licensure, numbers are written as 2,000, not two thousand.)

Exam Required: NCE

\author{
ALASKA \\ AK Division of Occupational Licensing \\ Board of Professional Counselors \\ P.O. Box 110806 \\ Juneau, AK 99811-0806 \\ (907) 465-2551 \\ (907) 465-2974 (fax) \\ Eleanor.vinson@alaska.gov \\ www.dced.state.ak.us/occ/ppco.htm \\ Title of License: LPC
}

Educational Requirements: Master's degree in counseling from a regionally or nationally accredited institution approved by the board and consisting of at least 60 graduate semester hours. The degree must include coursework in eight core areas. Related professional field includes psychology, marital and family therapy, social work, and applied behavioral science.

Experiential Requirements: 3,000 post-master's supervised hours including 1,000 hours of direct client contact and 100 hours of face-to-face supervision over a 2-year period. The supervisor must be a licensed mental health professional.

The face-to-face supervision can be by telephone or electronic means due to remote distances. Supervision must be under an LPC or other licensed mental health professional approved by the board.

Exam Required: NCE

\author{
ARIZONA \\ AZ Board of Behavioral Health Examiners \\ 3443 N. Central Avenue, Suite 1700 \\ Phoenix, AZ 85012 \\ (602) 542-1882 \\ (602) 364-0890 (fax) \\ Counseling Contact: \\ Pamela Osborn \\ Pamela.Osborn@azbbhe.us \\ www.azbbhe.us
}


Title of License: LPC

Licensed Associate Counselor (LAC) must practice only under direct supervision as prescribed by the board and shall not engage in independent practice.

Educational Requirements: Master's degree in counseling or a related field from a CACREP or CORE-accredited program or a program that includes a minimum of 60 semester hours and completion in 14 content areas. As of October 31, 2015: If a program is not accredited by CACREP or CORE, it must require 700 clinical supervision hours and a minimum of 24 semester hours in 8 content areas.

Experiential Requirements: 2 years/3,200 hours of full-time post-master's supervised work experience in psychotherapy, including assessment, diagnosis, and treatment. 100 hours of clinical supervision and 1,600 hours of direct client contact are required. No more than 400 of the additional hours can be psychoeducational.

Applicant must receive a minimum of 10 hours of clinical supervision obtained during direct observation or a review of audiotapes/videotapes by the clinical supervisor while the applicant is providing treatment and evaluation services to a client.

Exam Required: NCE, NCMHCE, or CRCE

\author{
ARKANSAS \\ AR Board of Examiners in Counseling \\ P. O. Box 989 \\ Little Rock, AR 72201 \\ (501) 683-5800 \\ (501) 683-6349 (fax) \\ arboec@sbglobal.net \\ www.state.ar.us/abec
}

Title of License: LPC

Licensed Associate Counselor (LAC): An applicant with less than 3 years of post-master's-level supervision experience, if all other requirements have been met.

Educational Requirements: Master's degree or higher in counseling from a program that reflects the CACREP or CORE curriculum and consists of 60 semester hours from a regionally accredited institution.

Experiential Requirements: 3 years/3,000 hours of post-master's supervised counseling experience ( 1 year $=1,000$ hours). $50 \%$ of the hours have to be Client Contact Hours.

One year of experience may be gained for each 30 semester hours earned beyond master's degree (up to 2 years) provided the hours are clearly counseling in nature and acceptable to the board. 
Supervision must be under an LPC approved by the board. Telephone supervision is allowed for less than $25 \%$ of the total amount.

Exam Required: NCE and an oral exam.

\section{CALIFORNIA}

CA Board of Behavioral Sciences

1625 N. Market Boulevard

Suite S-200

Sacramento, CA 95834

(916) 574-7830

(916) $574-8625$ (fax)

www.bbs.ca.gov

California Association for Licensed Professional Clinical Counselors

P.O. Box 280640

Northridge, CA 91328

www.calpcc.org

Title of License: Licensed Professional Clinical Counselor (LPCC) ${ }^{1}$

Professional Clinical Counselor Intern (PCCI): An unlicensed person who has completed the education requirements and is registered with the board to complete the supervision requirements to be licensed as an LPCC. (Has to renew annually for up to 5 years.)

Educational Requirements: Master's degree or higher that is counseling or psychotherapy in content:

Enrolled before 8/1/12 and graduate before 12/31/18: Minimum of 48 graduate semester hours.

Enrolled after 8/1/12 or graduate after 12/31/18: Minimum of 60 graduate semester hours.

\section{Additional Educational Requirements:}

1. 15 contact hours in alcoholism and other chemical substance abuse, dependency

2. 10 contact hours in human sexuality

3. A two-semester unit or three-quarter unit survey course in psychopharmacology

4. 15 contact hours in spousal or partner abuse assessment, detection, and intervention strategies ${ }^{1}$

5. 7 contact hours in child abuse assessment and reporting

6. 18 contact hours in California law and professional ethics for professional clinical counselors ${ }^{1}$ (possible that graduate coursework will suffice)

7. 10 contact hours in aging and long-term care ${ }^{1}$

8. 15 contact hours in crisis or trauma counseling ${ }^{1}$

${ }^{1}$ There are stipulations regarding the types of hours that will be accepted. Please consult your state regulations. 
Experiential Requirements: 3,000 hours of post-master's supervised counseling experience; 1,750 have to be Direct Client Contact hours.

Areas with guidance on:

- 500 hours maximum for group counseling

- 250 hours maximum for phone crisis counseling

- 150 hours minimum of clinical experience in a hospital or community mental health setting

- Combined total of 1,250 hours combined total maximum:

(A) Direct supervisor contact

(B) Client centered advocacy

(C) 250 hours maximum in administering tests

(D) 250 hours maximum in attending conferences

Exam Required: NCMHCE (as of January 1, 2014)—taken after experiential requirements have been fulfilled. AND: California jurisprudence exam-taken while acquiring supervision.

\section{COLORADO}

CO Division of Professions and Occupations

1560 Broadway, Suite 1350

Denver, CO 80202

(303) 894-7768

(303) 894-7764 (fax)

Karin.gleichauf@state.co.us

mentalhealth@dora.state.co.us

www.dora.state.co.us/mental-health

Title of License: LPC

Licensed Professional Counselor Candidate (LPCC)²: An applicant who has completed the education requirements and is under a licensed supervisor; valid for 4 years (if not registered as an LPCC, must register as a Registered Psychotherapist in the Registered Psychotherapist Board Database).

Educational Requirements: Master's degree or higher in professional counseling from a CACREP-accredited program, or equivalent program from a regionally accredited college/university consisting of 48 semester hours, completion of coursework in core areas and a practicum and/or internship. Note: If enrolled after August 31, 2014, the program must consist of 60 graduate semester hours.

Experiential Requirements: 2 years/2,000 hours of post-master's practice in applied psychotherapy under board-approved supervision. (Doctoral degree

${ }^{2}$ There are stipulations regarding the types of hours that will be accepted. Please consult your state regulations. 
can be 1,000 in 12 months). 100 hours of supervision is required, 70 of which must be face-to-face individual supervision.

The teaching of psychotherapy can count up to 600 hours and 30 hours of required supervision.

Note: Electronic supervision is allowed-initial 2-hour meeting must be in person and every 6 months an in-person meeting must be held and the electronic supervision must be audio and visual (as of July 20, 2012).

Exam Required: NCE and CO jurisprudence exam.

\section{CONNECTICUT}

CT Department of Public Health

Professional Counselor Licensure

410 Capitol Ave., MS\# 12APP

P. O. Box 340308

Hartford, CT 06134-0308

(860) 509-7603

(860) 509-8457 (fax)

oplc.dph@ct.gov

www.ct.gov/dph

Title of License: LPC

Educational Requirements: Master's degree or higher in counseling or a related mental health field from a regionally accredited institution of higher education consisting of at least 60 semester hours and completion of required coursework.

Experiential Requirements: 3,000 hours of post-master's supervised experience in professional counseling.

A minimum of 100 hours of direct supervision by an appropriately licensed individual is required.

Exam Required: NCE or NCMHCE

\section{DELAWARE}

DE Board of Mental Health and Chemical Dependency Professionals

Cannon Building

861 Silverlake Blvd.

Suite 203

Dover, DE 19904-2467

(302) 744-4500

(302) 739-2711 (fax)

www.dpr.delaware.gov 
Title of License: Licensed Professional Counselor of Mental Health (LPCMH) Licensed Associate Counselor of Mental Health (LACMH): An individual licensed for the purpose of gaining experience required for licensure as an LPCMH; must work under direct supervision of an LPCMH or other health professional approved by the board.

Educational Requirements: Master's degree or higher in clinical mental health, including a minimum of 48 semester hours.

Must also be certified by NBCC as a National Certified Counselor (NCC), or certified by another national mental health specialty certifying organization approved by the board.

Experiential Requirements: 2 years/3,200 hours full-time clinical professional counseling experience to be completed within a 4-year period.

1,600 hours must be under professional direct supervision acceptable to the board (100 hours must be face-to-face supervision; live video-conferencing is considered face to face but cannot exceed $50 \%$ of the supervision). 1,500 hours must be direct client contact hours ( 750 hours have to be individual).

30 graduate semester hours or more beyond master's degree may be substituted for 1 year/1,600 hours of required experience, provided that hours are clearly related to the field of counseling and acceptable to the board.

Note: If your degree was conferred after June 30, 2012, you will receive credit only for experience that you gained as a Delaware-licensed Associate Counselor of Mental Health.

\section{Exam Required: NCE or NCMHCE}

\section{DISTRICT OF COLUMBIA}

DC Board of Professional Counseling

Board of Professional Counseling

717 14th St. NW, Suite 600

Washington, DC 20005

(202) 724-4900

(877) 672-2174

(202) 727-8471 (fax)

hpla.doh.dc.gov/hpla

Title of License: LPC

Educational Requirements: 60 graduate semester hours including a master's degree in counseling or a related field from an accredited institution.

Master's degree to include coursework in 10 core areas, including a counseling practicum or internship.

Experiential Requirements: 2 years/3,500 hours of post-master's supervised professional counseling experience. 
200 hours of supervision (100 hours must be immediate supervision under an LPC).

\section{Exam Required: NCE}

Note: Will accept NCMHCE or CRCE if already taken in another jurisdiction.

\section{FLORIDA}

FL Board of Clinical Social Work, Marriage and Family Therapy, and Mental Health Counseling

4052 Bald Cypress Way, BIN C-08

Tallahassee, FL 32399-3258

(850) $245-4474$

(850) 921-5389 (fax)

mqa_491@doh.state.fl.us

www.doh.state.fl.us/mqa/491

Title of License: Licensed Mental Health Counselor (LMHC)

Provisional Mental Health Counselor: A person provisionally licensed to provide mental health counseling under supervision; valid for 24 months. Issued to licensure applicants who have completed their clinical experience requirement intending to provide services in Florida while satisfying coursework and/or exam requirements.

Educational Requirements: Master's degree or higher from a CACREPaccredited mental health counseling program that includes 60 semester hours, a course in human sexuality, and a course in substance abuse.

OR

Master's degree or higher from a program related to the practice of mental health counseling from an accredited institution that includes 60 semester hours, 12 specific course content areas, and 1,000 hours of supervised practicum, internship, or field experience.

AND for both options:

Completion of an 8-hour Laws and Rules course and a 2-hour Prevention of Medical Errors course from a board-approved provider

and within 6 months of licensure have to complete from a board-approved provider:

3-hour course on HIV and AIDS

2-hour domestic violence course from a board approved provider.

Experiential Requirements: 2 years of supervised post-master's clinical experience in mental health counseling that consists of at least 1,500 hours providing 
psychotherapy face-to-face with clients and at least 100 face-to-face hours of supervision (50 of which can be group supervision).

Supervision must be under an LMHC or equivalent.

Exam Required: NCMHCE

\section{GEORGIA}

GA Composite Board of Professional Counselors, Social Workers, and Marriage and Family Therapists

237 Coliseum Dr.

Macon, GA 31217-3858

(478) 207-2440

(866) 888-7127 (fax)

www.sos.state.ga.us/plb/counselors

Title of License: LPC

Associate Licensed Professional Counselor (ALPC): Applicant who has met the educational requirements and has registered with the board an acceptable contract for obtaining post-master's experience under direct supervision; valid for 5 years.

Educational Requirements: Master's degree or higher in a program that is primarily counseling in content, or in applied psychology, from an institution accredited by a regional body recognized by the Council on Higher Education Accreditation (CHEA).

Completion of specific coursework and a supervised practicum or internship consisting of at least 300 hours is required.

Experiential Requirements: 4 years/2,400 hours of supervised, post-master's directed experience in professional counseling in a work setting acceptable to the board, with a minimum of 120 clock hours of supervision (can count up to 1 year of experience from practicum/internship).

Note: On December 6, 2013, there was a proposal to increase the number of required hours to 3,000 .

A minimum of 2 years of supervision must be provided by an LPC. Please consult your state regulations for requirements regarding clinical supervision for licensure.

Exam Required: NCE 


\section{HAWAII}

HI Department of Commerce and Consumer Affairs-Professional and Vocational Licensing (PVL)

Mental Health Counselor Program

P. O. Box 3469

Honolulu, HI 96801

(808) 586-2697

counselor@dcca.hawaii.gov

www.hawaii.gov/dcca/areas/pvl/programs/mental

Title of License: LMHC

Educational Requirements: Master's degree or higher in counseling or an allied field related to the practice of mental health counseling, with a minimum of 48 semester hours (or 72 quarter hours) of coursework in core areas, from an accredited institution. Also, two academic terms of a supervised mental health practicum intern experience for graduate credit of at least 3 semester hours (or 5 quarter hours) per academic term in a mental health counseling setting, with at least 300 hours of supervised client contact under a licensed supervisor.

July 5, 2007: Changes in Hawaii Revised Statutes Chapter 453D-7(c)(1) and (2) allow individuals who obtained a graduate degree before July 1, 2007 an alternate method to verify the practicum and postgraduate experience.

Experiential Requirements: 2 years/3,000 hours of post-master's supervised experience in the practice of mental health counseling, with 100 hours of faceto-face clinical supervision under a licensed supervisor.

Experience shall be completed in no less than 2 years and in no more than 4 years.

\section{Exam Required: NCE}

Note: Will accept the NCMHCE or the CRCC (if taken after 1/1/2000 and before 7/1/2005).

\section{IDAHO}

ID State Licensing Board of Professional Counselors and Marriage and Family Therapists

700 W. State St.

Boise, ID 83702

(208) 334-3233

(208) 334-3945 (fax)

Deborah.Sexton@ibd.idaho.gov

cou@ibol.idaho.gov

www.ibol.idaho.gov 
Title of License: LCPC

LPC

Registered Counselor Intern (RCI): A counselor performing under supervision as part of the supervised experience requirement.

Educational Requirements: Master's degree or higher in a counseling field from an accredited college or university with 60 semester hours and completion of a 6-semester hour advanced counseling practicum.

Experiential Requirements: LPCC: Hold a valid LPC, 2 years/2,000 hours of supervised direct client contact experience accumulated after licensure in any state, 1,000 hours must be under supervision of an LCPC. Minimum of 1-hour face-to-face, one-on-one supervision for every 30 hours of direct client contact. Successful completion of a diagnostic evaluation graduate course or equivalent training/experience acceptable to the board.

LPC: 1,000 hours is defined as one thousand clock hours of experience working in a counseling setting, 400 hours of which shall be direct client contact. Supervised experience in practica and/or internships taken at the graduate level may be utilized. The supervised experience shall include a minimum of 1-hour face-to-face or one-to-one or one-to-two consultation with the supervisor for every 20 hours of job/internship experience. Face-to-face may include a faceto-face setting provided by a live video connection between the supervisor and supervisee. As stated under Subsection 150.01.a.iv, counseling practicum experience as opposed to job or internship experience shall be supervised at a ratio of 1 hour of supervision for every 10 hours in the settings. Supervised practicum and/or internship taken at a graduate level may be utilized.

Exam Required: LPCC: NCMHCE

LPC: NCE

\section{ILLINOIS}

IL Professional Counselor Licensing and Disciplinary Board 320 W. Washington St., 3rd Floor

Springfield, IL 62786

(217) 785-0800

(217) 524-6735 TDD

(217) 782-7645 (fax)

www.idfpr.com/DPRdefault.asp

or

www.idfpr.com/PROFS/Info/ProfCounselor.asp

Title of License: Licensed Clinical Professional Counselor (LCPC): Holds license authorizing independent practice of clinical professional counseling in private practice.

LPC: Holds license authorizing the practice of professional counseling. 
Educational Requirements: LCPC: A master's or higher in professional counseling or a related field from a regionally accredited college/university OR hold a current CCMHC credential issued by NBCC (meets all requirements for licensure as an LCPC).

Note: Certain other certifications meet all or part of the LPC or LCPC licensure requirements; please contact the board for more information.

LPC: Master's degree or higher in professional counseling or related field of at least 48 semester hours from a regionally accredited college/university in a program approved by the IL Dept. of Professional Regulation.

CACREP- and CORE-accredited programs in professional counseling are approved programs for both LPC and LCPC licensure.

Experiential Requirements: LCPC: 2 years/3,360 hours of full-time, satisfactory, supervised employment experience working as a clinical professional counselor in a professional capacity under the direction of a qualified supervisor, subsequent to degree.

Of these, 1,920 hours must be direct face-to-face service to clients.

One year = maximum of 1,680 hours, including 960 hours of direct face-toface service to clients.

If applicant holds a doctoral degree, 1 year must be subsequent to the degree and internships may count toward professional experience.

Exam Required: LCPC: NCE and NCMHCE or ECCP or CRCE LPC: NCE or CRCE

\section{INDIANA}

IN Behavioral Health and Human Services Licensing Board

402 W. Washington St., Rm. W072

Indianapolis, IN 46204

(317) 234-2064

(317) 233-4236 (fax)

pla5@pla.in.gov

www.in.gov/pla/social.htm

Title of License: LMHC

Licensed Mental Health Counselor Associate (LMHCA): A counselor performing under supervision as a part of the supervised experience requirement (required after July 1 , 2014)_cannot apply for until AFTER degree is conferred.

Educational Requirements: Master's degree or higher in an area related to mental health counseling from a CACREP- or CORE-accredited program, or equivalent program, from a regionally accredited institution, which includes 60 semester hours of graduate coursework in counseling in 12 specified content areas. 
Completion of a practicum (100 hours), internship (600 hours), and advanced internship (300 hours) with at least 100 hours of face-to-face supervision are required.

An area related to mental health counseling includes counseling, clinical social work, psychology, human services, human development, family relations, or programs accredited by CACREP or CORE.

Experiential Requirements: 3,000 hours of postgraduate supervised clinical experience over a 21- to 48-month period. Does not start to count until approved as an LMHCA.

100 hours of face-to-face supervision under an LMHC or equivalent supervisor is required.

\section{Exam Required: LMHC: NCMHCE \\ LMHCA: NCE}

Note: If a passing score is achieved on the initial try, the applicant can apply up to 1,500 hours accrued. If a passing score is not achieved, the applicant can no longer accrue hours until a passing score is achieved.

\section{IOWA}

IA Board of Behavioral Science Examiners

Lucas State Office Building, 5th Floor

321 E. 12th St.

Des Moines, IA 50319-0075

(515) 281-4422

(515) 281-3121 (fax)

Judith.Manning@idph.iowa.gov

www.idph.state.ia.us/licensure

Title of License: LMHC

Note: Can get a temporary license while meeting supervision requirementexpires in 3 years.

Educational Requirements: Master's degree or higher in mental health counseling from a CACREP-accredited program, or the content equivalent, with at least 60 semester hours (or equivalent quarter hours). For applicants who entered the program of study prior to July 1, 2010: 45 semester hours (or 60 quarter hours) are required. Degree must be from a nationally accredited college/university; or hold a current CCMHC credential issued by NBCC (meets educational and experience requirements). Applicants who did not graduate from CACREPaccredited mental health counseling program as of July 1, 2012 will need to submit to an education review.

Experiential Requirements: 2 years/3,000 hours of full-time, supervised postgraduate work experience in mental health counseling including 1,500 hours of 
direct client contact and 200 hours of clinical supervision concurrent with the work experience.

At least 100 of the 200 hours of clinical supervision must be individual supervision.

For applicants who entered a program of study prior to July 1, 2010: 2 years of full-time supervised postgraduate work experience in mental health counseling, including 200 hours of clinical supervision concurrent with 1,000 hours of mental health counseling conducted in person with individuals, couples, and families.

At least 100 of the 200 hours of clinical supervision must be individual supervision or hold a current CCMHC credential issued by NBCC (meets experience requirements).

Exam Required: NCE, NCMHCE, or CRCE

\section{KANSAS}

KS Behavioral Sciences Regulatory Board

712 S. Kansas Ave.

Topeka, KS 66603

(785) 296-3240

(785) 296-3112 (fax)

www.ksbsrb.org

Title of License: LCPC: May diagnose and treat mental disorders independently.

LPC: May practice under the direction of an LCPC, licensed psychologist, a person licensed to provide mental health services as an independent practitioner and whose license allows for diagnoses and treatment of mental disorders, or a person licensed to practice medicine and surgery.

Educational Requirements: LCPC: In addition to or as part of the graduate degree completion of 15 credit hours of supporting diagnosis and treatment of mental disorders with use of the American Psychiatric Association's Diagnostic and Statistical Manual of Mental Disorders (DSM), and a graduate-level supervised clinical practicum of professional experience.

LPC: 60 graduate semester hours, including a master's degree in counseling from a university approved by the board that consists of 45 graduate semester hours distributed among 10 core categories (this includes a supervised practicum).

Experiential Requirements: LCPC: Licensed as an LPC or meets all requirements to be licensed as an LPC, and 4,000 hours of supervised clinical professional counseling experience under an approved clinical training plan, which includes 1,500 hours of direct client contact and 100 hours of clinical supervision (50 must be individual supervision). 
Exam Required: LCPC: NCMHCE

LPC: NCE

KENTUCKY

KY Board of Licensed Professional Counselors

P.O. Box 1360

Frankfort, KY 40602

Diana Jarboe, Board Administrator: Diana.Jarboe@ky.gov

(502) 564-3296

(502) 564-4818 (fax)

lpc.ky.gov

Title of License: LPCC

Licensed Professional Counselor Associate (LPCA): Credential holder who has met all qualifications to engage in the practice of professional counseling under an approved clinical supervisor authorized by the board.

Educational Requirements: Master's degree or higher in professional counseling or a related field from a regionally accredited institution, with a minimum of 60 semester hours in nine specified areas and a 400-hour practicum/internship.

Experiential Requirements: No experiential requirements for LPCA.

LPCC: 4,000 hours of post-master's experience in the practice of counseling under approved supervision, which includes 1,600 hours of direct counseling and 100 hours of individual, face-to-face clinical supervision. Applicants are encouraged to include 10 hours of direct counseling with individuals in a jail or correctional setting as part of the 4,000 hours.

Exam Required: NCE or NCMHCE

\section{LOUISIANA}

LA Department of Licensed Professional Counselors Board of Examiners

8361 Summa Ave.

Baton Rouge, LA 70809

(225) $765-2515$

(225) 765-2514

lpcboard@eatel.net

www.lpcboard.org

Title of License: LPC

Counselor Intern: Those with a master's degree in counseling while practicing counseling under the board-approved supervision of an LPC. (There are three parts to registration and hours cannot begin to be accrued until all three are complete.)

Counselor interns have up to 7 years to complete their internship from the date of registration. 
Educational Requirements: Master's degree or higher, the substance of which is professional mental health counseling in content, from a regionally accredited institution, with 48 semester hours and coursework in eight content areas. Completion of a supervised practicum (100 hours) and a supervised internship (300 hours) in mental health counseling.

Beginning September 1, 2015, all applicants whose academic background has not been previously approved by the board must have accumulated at least 60 graduate semester hours as part of the graduate degree plan containing the eight required areas, the supervised mental health practicum, and supervised internship in mental health counseling (as defined in Chapter 5 in this textbook). Applicants may apply post-master's counseling courses toward licensure if their degree program consisted of less than 60 hours. Note: Rule change July 20, 2013.

Experiential Credentials: 2 years/3,000 hours of post-master's supervised experience in professional mental health counseling under the clinical supervision of a board-approved supervisor, to be completed in no more than 7 years. Hours to include: 1,900 to 2,900 hours of direct client contact in individual or group counseling; a maximum of 1,000 hours additional client contact, counseling-related activities, or education at the graduate level in the field of mental health; and a minimum of 100 hours of faceto-face supervision. Only 50 hours may be group supervision. Up to 25 of the hours can be synchronous videoconferencing. 500 hours of supervised experience may be gained for each 30 graduate semester hours beyond master's degree, but must have no less than 2,000 hours of supervised post-master's experience.

Exam Required: NCE or NCMHCE

\section{MAINE}

ME Board of Counseling Professionals Licensure

35 State House Station

Augusta, ME 04333

(207) 624-8674

(888) 577-6690

(207) 624-8637 (fax)

www.maine.gov/pfr/olr

Title of License: LCPC

\section{LPC}

Conditional LCPC: A license granted to an applicant for licensure as an LCPC who has met all the requirements except for the supervised clinical experience; valid for 2 years.

Conditional LPC: A license granted to an applicant for licensure as an LPC who has met all the requirements except for the supervised clinical experience; valid for 2 years.

Educational Requirements: LCPC/Conditional LCPC: Master's degree or higher from a regionally accredited institution that consists of 60 semester hours and 
is CACREP accredited, or consists of coursework in 10 core areas, 3 additional areas, and a practicum and internship of 900 clock hours.

LPC/Conditional LPC: Master's degree or higher from a regionally accredited institution that consists of 48 semester hours and is CACREP or CORE accredited, or consists of coursework in 10 core areas and a practicum and internship of 600 clock hours.

Experiential Requirements: LCPC: 2 years/3,000 hours of post-master's supervised clinical counseling experience $(4,000$ hours if qualifying degree did not have practicum/internship). To include 1,500 hours of direct client contact and 1 hour of clinical supervision per 30 hours of client contact with an approved supervisor.

LPC: 2 years/2,000 hours of post-master's supervised counseling experience. To include 1,000 hours of direct counseling and 67 hours of supervision with an approved supervisor.

Exam Required: LCPC: NCMHCE, LPC/Conditional LCPC/Conditional LPC: NCE

\section{MARYLAND}

MD Board of Examiners of Professional Counselors and Therapists

4201 Patterson Ave.

Baltimore, MD 21215

Anna.sullivan@maryland.gov

(410) 764-4732

(410) 358-1610 (fax)

www.dhmh.state.md.us/bopc

Title of License: LCPC

Licensed Graduate Professional Counselor (LGPC): Title used while fulfilling the supervised clinical experience requirement.

Educational Requirements: (Same for both license tiers.)

Master's degree or higher in professional counseling or related field from an accredited educational institution, with a minimum of 60 graduate semester hours in specific coursework, including completion of an alcohol and drug counseling course, and supervised field experience.

OR

Doctoral degree with a minimum of 90 graduate semester hours in counseling training approved by the board.

Experiential Requirements: 3 years/3,000 hours of supervised clinical experience in professional counseling ( 2 years/2,000 hours must be post-master's). 1,500 hours must be direct face-to-face client contact and 100 hours minimum of face-to-face clinical supervision. Supervision must be under a board-approved 
supervisor. At least half of hours need to be accumulated under the supervision of an LCPC approved by the board. If obtained a doctoral degree: 2 years/2,000 hours of supervised clinical experience in professional counseling ( 1 year/1,000 hours must be postdoctorate). 1,000 hours must be face-to-face client contact and 50 hours minimum of face-to-face clinical supervision. Supervision must be under a board-approved supervisor.

Exam Required: NCE and MD Professional Counselors and Therapists Act Exam

\section{MASSACHUSETTS}

MA Board of Registration of Allied Mental Health and Human Services Professionals

100 Washington St. Suite 710

Boston, MA 02118-6100

Board Administrator: leija.t.meadows@state.ma.us

(617) $727-3080$

(617) $727-1627$ (fax)

www.mass.gov/dpl/boards/mh

Title of License: LMHC

Educational Requirements: Minimum of 60 graduate semester hours in counseling or a related field from a regionally accredited institution of high education. This includes a minimum of 48 semester credit hour master's degree in mental health counseling or a related field, including a practicum (100 hours), an internship (600 hours), and coursework in each of the 10 content areas as defined by the board; or hold a current Certified Clinical Mental Health Counselor (CCMHC) credential issues by NBCC.

Experiential Requirements: 2 years/3,360 hours of full-time post-master's supervised clinical experience in mental health counseling after obtaining 60 graduate semester hours. To include 960 hours of direct client contact (250 hours may be group client contact), 130 hours of supervision ( 75 hours must be individual supervision and 25 hours must be under a LMHC). These hours do not include the pre-master's practicum and internship supervision requirements.

Exam Required: NCMHCE

MICHIGAN

MI Board of Counseling

P.O. Box 30670

Lansing, MI 48909

(517) 335-0918

(517) 373-2179 (fax)

bhphelp@michigan.gov

www.michigan.gov/healthlicense 
Title of License: LPC

Limited Licensed Professional Counselor (LLPC): A limited license is issued to those who have not yet completed the 3,000-hour supervised counseling experience; valid for 1 year and may be renewed.

Educational Requirements: (Same for both licenses.)

Master's degree or higher in professional counseling from a program that reflects the CACREP curriculum, including a minimum of 48 semester hours and 600 clock hour internship.

Experiential Requirements: 2 years/3,000 hours of postdegree supervised counseling experience. To include a minimum 100 hours under immediate physical presence of the supervisor. Supervision must be under an LPC. For persons with 30 semester hours or 45 quarter hours beyond the master's degree: 1 year/1,500 hours of postdegree supervised experience. To include a minimum of 50 hours under immediate physical presence of the supervisor. Supervision must be under an LPC. Note: Supervisors of LLPCs are required to have training in supervision.

Exam Required: NCE or CRCE

\section{MINNESOTA}

MN Board of Behavioral Health and Therapy

2829 University Ave. SE, Suite 120

Minneapolis, MN 55414

(612) 617-2178

(800) 627-3529 TTY

(612) 617-2187 (fax)

Bbht.board@state.mn.us

www.bbht.state.mn.us

Title of License: Licensed Professional Clinical Counselor (LPCC) 3

Licensed Professional Counselor-Independent designation.

Licensed Professional Counselor-Supervision designation (LPC), working on supervision hours toward LPC.

Educational Requirements: LPCC: Meet all LPC educational requirements, and in addition to or as part of the graduate degree in counseling or a related fieldcompletion of 24 graduate-level semester credits in six clinical content areas. LPC: Master's degree or higher in counseling or a related field from a CACREPaccredited program or regionally accredited institution recognized by the Council for Higher Education Accreditation (CHEA), which includes a minimum of 48 semester hours and supervised field experience not fewer than 700 hours that is counseling in nature.

The degree must include specific coursework in 10 core content areas.

${ }^{3}$ Has completed supervision experience for LPC licensure. 
Experiential Requirements: LPCC: Already has LPC credential; 4,000 hours of post-master's supervised professional practice in the delivery of clinical services in the diagnosis and treatment of mental illnesses and disorders in both children and adults. Supervision must comply with the board's Supervision Contract for LPCC applicants. Practice must include 1,800 hours of clinical client contact. At least $50 \%$ of supervision must be individual supervision. Supervisor must have independent CLINICAL license.

LPC: 2,000 hours of post-master's supervised professional practice that is acceptable to the board OR submission of Supervision Plan for the first 2,000 hours of professional practice. Supervision must be completed in not less than 1 year and not more than 3 years. Practice must include 100 hours of supervision under a board-approved supervisor.

Exam Required: LPCC: NCMHCE. Note: ECCP is no longer offered by NBCC. LPC: NCE or other national exam that is determined by the board to be substantially similar to the NCE.

\section{MISSISSIPPI}

MS State Board of Examiners for Licensed Professional Counselors

239 North Lamar St., Suite 402

Jackson, MS 39201

LeAnn Mordecai, Executive Director: LPMordecai@lpc.ms.gov

(601) 359-1010

(888) 860-7001

(662) 716-3021 (fax)

infor@lpc.ms.gov

Title of License: LPC

Licensed Professional Counselor: An applicant who has satisfied experience and educational requirements but still needs to pass the exam.

Educational Requirements: Master's degree or educational specialists degree in counselor education or a related program from a regionally or nationally accredited college/university program, subject to board approval, with 60 semester hours (or 90 quarter hours) and completion of coursework in 10 content areas, or doctoral degree primarily in counseling, guidance, or related counseling field from a regionally or nationally accredited college/university program, subject to board approval, with 60 semester hours (or 90 quarter hours) and completion of coursework in 10 content areas.

Experiential Requirements: 2 years/3,500 hours of supervised counseling experience in a clinical setting ( 1,750 hours must be post-master's experience). 1,167 hours must be direct counseling service to clients to include counseling-related activities. Minimum of 100 hours of supervision required 
(50 hours may be group supervision). Supervision must be under an LPC that has met the requirements to be a MS Board Qualified Supervisor.

Exam Required: NCE; will accept the NCMHCE but not required.

\section{MISSOURI}

MO Committee for Professional Counselors

3605 Missouri Blvd.

P.O. Box 1335

Jefferson City, MO 65102

profcounselor@pr.mo.gov

Loree.Kessler@pr.mo.gov

pr.mo.gov/counselors.asp

Title of License: LPC

Counselor-in-Training: Issued automatically when supervision is registered and approved and all other requirements are met.

Educational Requirements: Master's degree or higher in counseling, counseling psychology, or school psychology from a regionally accredited college or university, with at least 48 semester hours reflecting the CACREP or CORE curriculum, and a practicum, internship, or field experience consisting of 6 semester hours in the practice of counseling.

Experiential Requirements: 2 years/3,000 hours of post-master's continuous experience (full or part time), to be completed within 60 months. 1,200 hours must be direct client contact. 30 hours of post-master's study may be substituted for 1,500 of the 3,000 hours.

If a doctorate or specialist's degree: 1 year/1,500 hours of counseling experience (full or parttime), to be completed within 36 months; 600 hours must be direct client contact.

For both degree paths: 15 hours of supervised counseling experience per week are required, with 1 hour a week of face-to-face supervision. If electronic supervision is continuously interactive, it can count toward required hours. Supervision must be under an LPC or licensed psychologist or psychiatrist approved and registered with the board.

\section{Exam Required: NCE}

\section{MONTANA}

MT Board of Social Work Examiners and Professional Counselors

301 S. Park 4th Fl.

P.O. Box 200513

Helena, MT 59620

dlibsdswp@state.mt.us

www.swpc.mt.gov 
Title of License: LCPC

Educational Requirements: A 60-semester hour (or 90-quarter hour) counseling-in-nature graduate degree from an accredited institution that includes specific coursework and a 6-semester hour advanced counseling practicum, or applicants may apply for licensure with a minimum of 45 semester hours (67.5 quarter hours) master's degree in counseling that includes specific coursework and a 6-semester hour advanced counseling practicum. Applicants must complete the remaining hours within 5 years of the original application approval date. Applicants are not eligible for full licensure, nor are they eligible to test until the hours are completed.

Experiential Requirements: 3,000 hours of supervised counseling experience, 1,500 hours of which must be postdegree. 1,000 of the 1,500 hours must be direct client contact (250 can be group). Must have 1 hour of supervision for every 20 hours. Supervision must be under a licensed professional counselor or licensed allied mental health professional who has had 20 clock hours of supervision training and the agreement has been approved by the board.

Exam Required: NCE

NEBRASKA

NE Board of Mental Health Practice

P.O. Box 94986

Lincoln, NE 68509

(402) 471-0185

(402) 472-3577 (fax)

Program Manager: kris.chiles@nebraska.gov

www.dhhs.state.ne.gov/crl/mhcs/mental/mentalindex.htm

Title of License: Licensed Mental Health Practitioner-Certified Professional Counselor (LMHP-CPC) or Licensed Professional Counselor (LPC): This additional appellation is available for LMHPs who have a graduate degree from a CACREP-accredited program or a program with equivalent coursework.

Licensed Mental Health Practitioner (LMHP): An individual who is qualified to engage in mental health practice or offers or renders mental health practice services.

Provisional Licensed Mental Health Practitioner (PLMHP): An individual beginning the 3,000-hour experience requirement; valid for 5 years.

Educational Requirements: Master's degree or higher from an approved educational program that is primarily therapeutic mental health in content, in a CACREP-accredited program (or complete equivalent coursework), from a regionally accredited institution. Completion of a practicum or internship with a minimum of 300 clock hours of direct client contact under the supervision of a qualified supervisor. 
Experience Requirements: LMHP-CPC/LPC, LMHP: 3,000 hours of post-master's supervised experience in mental health practice accumulated during the 5 years immediately preceding application for licensure. To include a 1,500 hours of direct client contact (not more than 1,500 hours of nondirect service). Supervision must be under an LMHP, LIMPH, licensed psychologist or licensed physician with mental health treatment training.

Exam Required: LIMHP and LMHP with CPC credential: NCE of NCMHCE

\section{NEVADA}

The Board of Examiners for Marriage and Family Therapists and Clinical Professional Counselors

P.O. Box 370130

Las Vegas, NV 89134-0130

(702) 486-7388

(702) 486-7258

nvmftbd@mftbd.nv.gov

www.marriage.state.nv.us

Title of License: Licensed Clinical Professional Counselor (LCPC)

Licensed Clinical Professional Counselor Intern

Educational Requirements: (Same for both licenses.)

Master's degree or higher in mental health counseling or community counseling from a program approved by CACREP or equivalent program of at least 48 semester hours and completion of the minimum required coursework, including 3-semester hour courses or 4-quarter hour courses in Supervised Clinical Practice by way of either practicum or internship in mental health counseling, accomplished over a period of 1 academic year.

Experiential Requirements: 2 years/3,000 hours of post-master's supervised counseling experience. To include 1,500 hours of direct client contact, 1,200 hours in the practice of clinical professional counseling, and 100 hours of direct supervision under an approved supervisor of which at least 1 hour per week was completed for each work setting at which the applicant provided counseling.

Exam Required: NCMHCE

\section{NEW HAMPSHIRE}

NH Board of Mental Health Practice

121 S. Fruit St.

Concord, NH 03301

mlynch@dhhs.state.nh.us

(603) 271-6762

(800) 735-2954 TDD

(603) 271-3950

www.nh.gov/mhpb 
Title of License: LCMHC

Educational Requirements: All applicants shall have a master's degree or doctoral degree in clinical mental health counseling from a CACREP-accredited institution or have a 60 credit degree in clinical mental health counseling or its equivalent from an institution which has received regional accreditation from the Association Secondary Schools and Colleges. A minimum of 1 academic year of full-time graduate study in mental health counseling should be completed in residence at the institution granting the college degree. There are 11 content areas.

Experiential Requirements: 2 years/3,000 hours of paid post-master's supervised clinical work experience in a mental health setting, to be completed in no more than 5 years. Each year shall not be less than 1,500 clock hours. 100 hours of face-to-face supervision provided by a state-licensed, board approved, mental health professional is required.

Exam Required: NCMHCE and an essay exam provided by the board.

\section{NEW JERSEY}

NJ Board of Marriage and Family Therapy Examiners, Professional Counselor Examiners Committee

P.O. Box 45007

Newark, NJ 07101

(973) 504-6415

(973) 648-3536 (fax)

www.state.nj.us/lps/ca/medical/procounsel.htm

Title of Credential: LCMHC, LPC

Licensed Associate Counselor (LAC): After acceptable documentation of the satisfaction of the LPC education and examination requirements, an individual may be granted licensure as an Associate Counselor to practice counseling under the direct supervision of an LPC or a supervisor acceptable to the committee.

Educational Requirements: Minimum of 60 graduate semester hours, which include a master's degree in counseling from a regionally accredited institution of higher education ( 45 of 60 hours must be distributed in eight of the nine defined course content areas).

As of April 20, 2006, an acceptable graduate degree means that the word "counseling" or the word "counselor" appears in the title of the graduate degree awarded and that the institution offering the degree states in the catalog or in another format acceptable to the committee that the purpose of the graduate degree is to prepare students for the professional practice of counseling. 
Experiential Requirements: LCMHC: Already holds an LPC. Certification by the Academy of Certified Clinical Mental Health Counselors, or any successor thereto; passage of a comprehensive qualifying examination prepared by the Academy; evidence satisfactory to the committee that the clinical mental health counselor has satisfied the continuing education requirements of the committee; and evidence satisfactory to the committee that certification of the clinical mental health counselor has been renewed by the Academy. 2 years/3,000 hours of post-master's degree supervised field experience, 100 hours of face-to-face supervision.

LPC: 3 years of full-time supervised counseling experience in a professional counseling setting, 1 year of which may be obtained prior to the granting of the master's degree. 1 year/1,500 hours of the experience may be eliminated by substituting 30 graduate semester hours beyond the master's degree. In no case may an applicant have less than 1 year of post-master's supervised work experience.

LAC: No experiential requirements.

Exam Required: NCE

NEW MEXICO

NM Counseling and Therapy Practice Board

2550 Cerrillos Rd.

Santa Fe, NM 87505

(505) 476-4610

(505) 476-4633 (fax)

counselingboard@state.nm.us

www.rld.state.nm.us/counseling

Title of License: LPCC

LMHC: An individual who is pursuing the LPCC license but still needs to complete the supervised experience requirement.

Educational Requirements: Master's degree or higher in counseling or a counseling-related field with no less than 48 graduate hours from an accredited institution. Related field degree must meet the clinical core curriculum. Counseling-related field is mental health, community counseling, agency counseling, psychology, clinical psychology, family studies, art therapy, or education.

Experiential Requirements: 2 years of postgraduate professional clinical counseling experience, with 3,000 hours of clinical client contact and a minimum of 100 hours of face-to-face supervision. 1,000 hours of clinical client contact may come from the applicant's internship/practicum. Supervision must come from an LPCC or licensed MFT, professional art therapist, psychiatrist, clinical psychologist, or independent social worker.

Exam Required: LPCC: NCE, and NCMHCE 


\section{NEW YORK}

NY State Education Department

State Board for Mental Health Practitioners

Office of the Professionals

89 Washington Ave., 2nd Floor

Albany, NY 12234-1000

(518) 474-3817 x450

(518) 486-2981 (fax)

mhpbd@mail.nysed.gov

www.op.nysed.gov/mhclic.htm

Title of License: LMHC

Limited Permit: Applicants who have met all requirements except experience and/or exam may apply for a 2-year permit to practice under supervision; may be renewed for one year, upon new application and permit fee.

Educational Requirements: Master's degree or higher in counseling that includes 60 semester hours and completion of specific coursework. Note: If counseling degree was completed prior to January 1, 2010, 48 credit hours were required. Completion of a 1-year/600 clock hours supervised internship or practicum in mental health counseling. Completion of coursework or training approved by the education department in the identification and reporting of child abuse.

Experiential Requirements: Completion of a minimum of 3,000 hours of post-master's supervised experience providing mental health counseling in a setting acceptable to the department. 1,500 of the hours must be direct client contact.

\section{Exam Required: NCMHCE}

\section{NORTH CAROLINA}

NC Board of Licensed Professional Counselors

P.O. Box 1369

Garner, NC 27529

(919) 661-0820

(919) 779-5642 (fax)

ncblpc@mgmt4u.com

www.ncblpc.org

Title of License: LPC

Licensed Professional Counselor Associate (LPCA): Individuals who are pursuing the LPC license but still need to complete the supervised experience requirements.

Educational Requirements: Master's degree or higher in counseling from a regionally accredited institution of higher education that includes coursework in nine areas of study and meets the following additional requirements: 
- If enrolled prior to July 1, 2009, 48 semester hours (or 72 quarter hours) are required.

- If enrolled prior to July 1, 2013, but after June 30, 2009, 54 semester hours (or 81 quarter hours) are required.

- If enrolled after June 30, 2013, 60 semester hours (or 90 quarter hours) are required.

A practicum and internship must be completed as part of the graduate course of study:

- Must cover at least a combined total of 17 hours of graduate counseling supervision.

- Must consist of a combined minimum of 300 hours of supervised graduate counseling experience at a rate of not less than 1 hour of clinical supervision per 40 hours of graduate counseling experience.

- At least $60 \%$ of this counseling experience shall be direct graduate counseling experience.

Experimental Requirements: 3,000 hours of supervised professional practice; 2,000 hours must be direct counseling. No hours can be applied from the practicum/internship. Not less than 8 hours per week but no more than 40 hours per week. 100 hours of clinical supervision required. 75 hours must be individual supervision. Must have a minimum of 1 hour of clinical supervision for every 40 hours of professional practice. Supervision shall be based on direct (live) observation, co-therapy, audio and video recordings, and live supervision. Supervisor must be approved by the board.

Exam Required: LPC/LPCA: NCE, NCMHCE, or CRCE and NC jurisprudence exam

LPCA: NCE, NCMHCE, or CRCE

NORTH DAKOTA

ND Board of Counselor Examiners

2112 10th Ave. SE

Mandan, ND 58554

(701) 667-5969

(701) 667-5969 (fax)

ndbce@btinet.net

www.ndbce.org

Title of License: LPCC

LPC: Full professional license after LAPC criteria are met and supervised experience has been completed.

Licensed Associate Professional Counselor (LAPC): A 2-year license, which allows for completion of the supervised experience. A 2-year plan of supervision and passage of the NCE required. 
Educational Requirements: LPCC: Master's degree in counseling from an accredited college or university, including 60 semester hours, core clinical coursework (a minimum of 15 contact hours in each of three categories determined by the board), and 800 hours of clinical training in a supervised practicum and internship.

LPC/LAPC: Master's degree in counseling or closely related field from an accredited college or university including 48 semester hours and specific core counseling coursework within the master's degree.

Experiential Requirements: LPCC: Must already possess the first-level LPC credential, and 2 years/3,000 hours of post-master's supervised clinical counseling experience in a clinical setting. Experience to include 100 hours of direct supervision ( 60 hours must be individual, face-to-face supervision) by a board-approved supervisor.

LPC: 400 hours of direct client counseling contact during the 2-year LAPC supervisory period. Experience to include 100 hours of direct supervision (60 hours must be individual, face-to-face supervision) by a board-approved supervisor.

Exam Required: LPCC: NCMHCE and a videotaped clinical counseling session of at least 30 minutes.

LPC/LAPC: NCE

\section{$\mathrm{OHIO}$}

$\mathrm{OH}$ Counselor, Social Worker, and Marriage and Family Therapist Board 50 W. Broad St., Suite 1075

Columbus, $\mathrm{OH} 43215$

(614) 466-0912

(614) 728-7790 (fax)

Cswmft.info@cswb.state.oh.us

www.cswmft.ohio.gov

Title of License: Licensed Professional Clinical Counselor (LPCC)

Professional Counselor/Clinical Resident (CR): Title used while completing the 3,000 hours of supervised experience required for the $\mathrm{LPCC}$ license.

LPC: Title used after completing coursework including practicum and internship.

Registered Counselor Trainee (RCT): Title used while enrolled in a practicum or internship in a counselor education program.

Educational Requirements: Master's degree or higher in counseling from an accredited program, with 60 semester (or 90 quarter) hours, from an accredited institution. 20 hours (or 30 quarter hours) must be in clinical content areas. 100 hours practicum and 600 hours internship required. 
Experiential Requirements: LPCC: Must already possess the first-level LPC credential and 2 years $/ 3,000$ hours of post-master's clinical counseling under the supervision of an LPCC holding the supervision credential. $50 \%$ must be clinical experience. The supervision must include the diagnosis and treatment of mental and emotional disorders; $50 \%$ of the time must be face-to-face contact delivering clinical counseling services. Supervisor will fill out an evaluation to evaluate competence to diagnose and treat mental and emotional disorders. No experiential requirements for LPC, CR/RCT.

Exam Required: LPCC: NCMHCE

$$
\begin{aligned}
& \text { LPC: NCE } \\
& \text { OH jurisprudence exam }
\end{aligned}
$$

OKLAHOMA

OK State Board of Licensed Professional Counselors

1000 N.E. 10th St.

Oklahoma City, OK 73117

(405) 271-6030

(405) 271-1918 (fax)

nenaw@health.ok.us

pcl.health.ok.gov

Title of License: LPC

Licensed Professional Counselor Candidate: An individual may be granted licensure as Licensed Professional Counselor Candidate to practice counseling under the direct supervision of an approved LPC supervisor.

Educational Requirements: Master's degree or higher in counseling or a related mental health field with 60 graduate semester hours (or 90 quarter hours) from a regionally accredited college or university. Completion of coursework in 10 areas and a counseling practicum/internship of 300 clock hours. The board will define what qualifies as counseling related.

Experiential Requirements: 3 years/3,000 hours full-time postapplication professional counseling experience supervised by an approved LPC supervisor. For each 1,000 hours, 350 hours must be direct face-to-face contact. Faceto-face supervision must be 45 minutes for every 20 hours of experience. Up to 2 years of required experience may be gained at a rate of 1 year for each 30 graduate semester hours beyond the master's degree, provided that such hours are clearly related to the field of counseling and acceptable to the board. The applicant shall have no less than 1 year of supervised-time experience in counseling.

Exam Required: NCE and Oklahoma Legal and Ethical Responsibilities Exam (as pertains to LPCs) 


\section{OREGON}

OR Board of Licensed Professional Counselors and Therapists

3218 Pringle Rd., SE, Suite 250

Salem, OR 97301-6312

(503) 378-5499

(503) 373-1427 (fax)

Lpc.lmft@state.or.us

www.oregon.gov/pblpct

Title of License: LPC

Registered Intern: An applicant registered to obtain postdegree supervised work experience toward licensure.

Educational Requirements: Master's degree or higher in counseling, with 48 semester hours in a CACREP- or CORE-accredited program, or the content equivalent, from a regionally accredited institution. Completion of an internship/practicum consisting of 600 clock hours. If graduating after October 1 , 2014: Master's degree or higher in counseling, with 60 semester hours (or 90 quarter hours) in a CACREP- or CORE-accredited program, or the content equivalent, from a regionally accredited institution.

Experiential Requirements: 3 years of full-time supervised experience in counseling, to include 2,400 hours of direct client contact. The supervision must take place concurrently with the direct client contact hours and must total no less than 2 hours of supervision for months where 45 or fewer direct client contact hours are completed, or total no less than 3 hours of supervision for months where 46 or more direct client contact hours are completed. Up to $75 \%$ of the individual supervision can be electronic and 50\% of total supervision can be group. An approved supervisor must provide supervision. 600 (from 48 credit hours) or 700 (from 60 credit hours) client contact hours may be obtained during the clinical portion of the qualifying degree program.

Exam: NCE, CRCE, NCMHCE, or other exam as approved by the board and Oregon Law and Rules (open book).

\section{PENNSYLVANIA}

PA State Board of Social Workers, Marriage and Family Therapists, and Professional Counselors

One Penn Center

2601 N. 3rd St.

Harrisburg, PA 17110

(717) 783-1389

(717) 787-7769 (fax)

ra-socialwork@pa.gov

stsocialwork@state.pa.us

www.dos.state.pa.us/social 
Title of License: LPC

Educational Requirements: Successful completion of a planned program of 60 semester hours (or 90 quarter hours) of graduate coursework in counseling or a field closely related to the practice of professional counseling, including a 48 semester hours (or 72 quarter hours) master's degree in professional counseling or in a field closely related to the practice of professional counseling.

OR a doctoral degree in counseling or in a field closely related to the practice of professional counseling.

AND for both: Completion of coursework in nine core areas including a supervised practicum (100 hours) and internship (600 hours). The supervised internship experience shall begin after completion of the supervised practicum experience.

Experiential Requirements: 3 years/3,600 hours of supervised clinical experience after completing 48 graduate-level credits (or 72 quarter hours). (Have to complete at least 600 hours a year and no more than 1,800 a year.) If obtained a doctoral degree in counseling: 2 years/2,400 hours of supervised clinical experience. 1 year/1,200 hours must be obtained postdegree.

Supervision must be provided by a qualified supervisor. At least 1,800 hours must be completed under an LPC that has 5 years of experience within the last 10 years as a professional counselor. There should be 2 hours of supervision for every 40 hours of client hours. The remaining hours may be completed under an individual that holds a license and has at least a master's degree in a related field and 5 years of experience within the last 10 years in that field.

Exam Required: Any one of the following: NCE, CRCE, ATCB, CBMT, PEPK, AAODA, EMAC

PUERTO RICO

PR Office of Regulation and Certification of Health Professions

Board of Examiners of Professional Counselors

P.O. Box 10200

San Juan, PR 00908

(787) 723-0102

www.salud.gov.pr

Title of License: Licensed Professional Counselor (LPC)

Professional Counselor with Provisional License (PCPL):

Person who is granted a temporary/provisional authorization by the board to offer counseling services under supervision to meet the experience requirement; valid for 3 years.

Certified Mentor (CM): A licensed PC who has been certified by the board to supervise those who wish to obtain licensure. 
Educational Requirements: Master's degree or higher in counseling from an institution accredited by the Council of Higher Education of Puerto Rico. Specific coursework required in 8 out of 10 areas.

Experiential Requirements: Completion of a minimum of 500 hours of practice supervised by a CM. Upon approval of the exam required, the board shall issue a provisional license.

Exam Required: NCE

\section{RHODE ISLAND}

RI Board of Mental Health Counselors and Marriage and Family Therapists

3 Capitol Hill, Rm. 104

Providence, RI 02908

(401) 222-2828

(401) 222-1272

www.health.ri.gov/hsr/professions/mfcounsel.php

Title of License: Licensed Clinical Mental Health Counselor (LCMHC)

Educational Requirements: Master's degree or higher specializing in counseling/ therapy from a college/university accredited by the New England Association of Schools and Colleges or an equivalent regional accrediting agency. OR master's degree, certificate in advanced graduate studies, or a doctoral degree in mental health counseling or allied field from a recognized educational institution.

For all options: Completion of 60 semester hours (90 quarter hours) (master's must be 48 semester hours or 72 quarter hours) within the graduate counseling/ therapy program, coursework in eight core areas, a supervised practicum (12 semester hours), and 1 calendar year of a supervised internship consisting of 20 hours per week in counseling.

Experiential Requirements: 2 years/2,000 hours of direct client contact offering clinical or counseling or therapy services with emphasis in mental health counseling. To include 100 hours of post-master's supervised casework spread over a 2-year period. Supervision must be under a board-approved supervisor.

\section{Exam Required: NCMHCE}

\section{SOUTH CAROLINA}

SC Board of Examiners for the Licensure of Professional Counselors, Marriage and Family Therapists, and Psychoeducational Specialists

P.O. Box 11329

Columbia, SC 29211-1329

(803) 896-4658

(803) 896-4719 (fax)

www.llr.state.sc.us/pol/counselors 
Title of License: LPC

Professional Counselor Intern (LPC/I): An applicant who has met the education and exam requirements, but not the 2-year supervised experience requirements.

Educational Requirements: Master's degree or higher in professional counseling or a related discipline from a regionally accredited institution that includes at least 48 graduate hours, coursework in 10 content areas, and a 150 hours supervised counseling practicum.

Experiential Requirements: Must already possess the first-level LPC/I credential, and 2 years/1,500 hours of full-time, post-master's supervised clinical experience in the practice of professional counseling. The 1,500 hours must be direct counseling with individuals, couples, families, or groups. A minimum of 150 hours of the 1,500 hours must be clinical supervision provided by a board-approved LPC supervisor (100 hours must be individual supervision).

Exam Required: NCE or NCMHCE

\section{SOUTH DAKOTA}

SD Board of Examiners for Counselors and Marriage and Family Therapists P.O. Box 2164

Sioux Falls, SD 57101

(605) 331-2927

(605) 331-2043 (fax)

sdbce.msp@midconetwork.com

www.counselor.sd.us

Title of License: Licensed Professional Counselor-Mental Health (LPC-MH) LPC

Educational Requirements: Master's degree or higher with an emphasis in mental health counseling from a CACREP-accredited program, or equivalent program from an accredited institution that includes specific coursework and a supervised practicum (100 hours) and internship (600 hours). 48 semester hours required for LPC licensure; 60 semester hours or completion of all required coursework for LPC-MH licensure.

Experiential Requirements: LPC-MH: Must already possess the first-level LPC credential. 2 years/2,000 hours of post-master's direct client contact in a clinical setting and 100 hours of direct supervision, at least 50 hours of which shall be face-to-face. 1,000 hours of post-master's direct client contact hours and 50 hours of face-to-face supervision earned under the LPC credential may be counted toward these requirements if LPC-MH supervision condition were met. 
LPC: 2,000 hours of post-master's counseling experience, with 800 hours of direct client contact and 100 hours of direct supervision, at least 50 hours of which shall be face-to-face.

Exam Required: LPC-MH: NCMHCE

$$
\text { LPC: NCE }
$$

\section{TENNESSEE}

TN Board for Professional Counselors, Marital and Family Therapists, and Clinical Pastoral Therapists

227 French Landing, Suite 300

Nashville, TN 37243

(615) 532-3202, ×25138

(800) $778-4123, \times 25138$

(615) 532-5369 (fax)

health.state.tn.us/boards/pc mft\&cpt

Title of License: Licensed Professional Counselor-Mental Health Service Provider (LPC/MHSP)

LPC

Educational Requirements: LPC/MHSP: In addition to or as part of the graduate-degree completion of 9 graduate semester hours of coursework related to diagnosis, treatment, appraisal, and assessment of mental disorders.

LPC: 60 graduate semester hours in professional counseling or a related field from an institution accredited by the Southern Association of Colleges and Schools, CACREP, or a comparable accrediting body, which includes a master's degree in professional counseling and a supervised 500-hour practicum or internship (300 hours of which must be completed in a clinical setting).

Experiential Requirements: LPC/MHSP: 2 years of post-master's professional experience consisting of 3,000 hours of direct clinical experience (not less than 10 hours per week); 1,500 hours have to be direct client contact and 1,500 hours need to be clinically based. Must have 150 hours of supervision.

LPC: 2 years of post-master's professional experience consisting of 3,000 hours of direct clinical experience (not less than 10 hours per week). Note: As of January 31,2013 , supervisors had to be licensed for 5 years, conform to section $F$ of the ACA Code of Ethics, and have at least 12 clock hours of supervision training.

Exam Required: LPC/MHSP: NCMHCE, NCE, and TN jurisprudence exam all required.

LPC: NCE and TN jurisprudence exam 
TEXAS

TX State Board of Examiners of Professional Counselors

P.O. Box 149347, MC 1982

Austin, TX 78714

(512) 834-6658

(512) 834-6677 (fax)

lpc@dshs.state.tx.us

www.dshs.state.tx.us/plc

Title of License: LPC

Licensed Professional Counselor Intern (LPC-I): An applicant practicing under supervision; valid for 5 years.

Educational Requirements: Master's degree or higher in professional counseling or related field from and accredited college/university consisting of 48 graduate semester hours. Completion of specific coursework and a 300 clock hour supervised practicum with at least 100 hours of direct client contact. Counseling-related field: A mental health discipline utilizing human development, psychotherapeutic, and mental health principles including, but not limited to, psychology, psychiatry, social work, marriage and family therapy, and guidance and counseling. Non-counseling-related fields include, but are not limited to, sociology, education, administration, dance therapy, and theology.

Experiential Requirements: 3,000 hours of post-master's supervised experience, including 1,500 hours of direct client contact. Supervision must be provided by under a board-approved LPC.

Exam Required: NCE and Texas jurisprudence exam

\section{UTAH}

UT Professional Counseling Licensing Board

P.O. Box 146741

Salt Lake City, UT 84114

(801) 530-6628

(866) 275-3675 (Utah toll-free number)

(801) 530-6511 (fax)

dopl.utah.gov/licensing/professional counseling.html

Title of License: LCMHC

Licensed Associate Clinical Mental Health Counselor: LACMHC credential required before starting the supervised experience requirement; valid for 3 years.

Educational Requirements: Master's degree or higher in mental health counseling from a CACREP-accredited program, including a minimum of 60 graduate semester hours (or 90 quarter hours) in specific coursework. A minimum of 
3 semester hours or $4 \frac{1}{2} 2$ quarter hours of a practicum. A minimum of 6 semester hours or 9 quarter hours of an internship.

Experiential Requirements: Must already possess the LACMHC. 4,000 hours of post-master's supervised professional counseling experience. 1,000 hours must be supervised experience in mental health therapy. 100 hours of face-to-face supervision required. Supervision must be under a licensed mental health therapist on site with a contract.

Exam Required: NCE, NCMHCE, and the Utah Professional Counselor Law, Rules, and Ethics Exam.

\section{VERMONT}

VT Board of Allied Mental Health Practitioners

89 Main St., 3rd Floor

Montpellier, VT 05620

(802) 828-2390

(802) 828-2465 (fax)

dlafaill@sec.state.vt.us

vtprofessionals.org

Title of License: LCMHC

Educational Requirements: Master's degree or higher in counseling from an accredited institution, with a minimum of 60 semester hours and 1,000 hours of a supervised practicum, internship, or field experience in a clinical mental health setting. (Master's degree must be 48 semester hours.)

Experiential Requirements: 2 years/3,000 hours of post-master's experience in clinical mental health counseling, including 2,000 hours of direct client contact. 100 hours of face-to-face supervision required. Supervision should be 1 hour per 30 client hours and 50 must be individual supervision. Supervision must be under a board-approved Licensed Mental Health Professional.

Exam Required: NCE and NCMHCE and VT jurisprudence exam

\section{VIRGINIA}

VA Board of Counseling Perimeter Center

9960 Mayland Drive, Suite 300

Richmond, VA 23233

(804) 367-4610

(804) 527-4435 (fax)

coun@dhp.virginia.gov

www.dhp.virginia.gov/counseling 
Title of License: LPC

Licensed Professional Counselor Resident: An applicant practicing under supervision.

Educational Requirements: Master's degree or higher in counseling that includes 60 semester hours (or 90 quarter hours) of graduate study in counseling. Completion of a supervised internship consisting of at least 600 hours. Programs that are approved by CACREP or CORE are recognized as meeting the definition of graduate degree programs that prepare individuals to practice counseling and counseling treatment intervention.

Experiential Requirements: 4,000 hours of postgraduate supervised counseling experience, including 2,000 hours of direct client contact. 200 hours of supervision required (100 hours must be under the supervision of an LPC approved by the board). Graduate-level internship hours may count toward the 4,000 hours.

Exam Required: NCMHCE

\section{WASHINGTON}

WA Licensed Mental Health Counselors, Marriage and Family Therapists, and Social Workers Advisory Committee

P.O. Box 47877

Olympia, WA 98504-7877

(360) 236-4700

(360) 236-4818 (fax)

hpqa.csc@doh.wa.gov

www.doh.wa.gov/licensing

Title of License: LMHC

Licensed Mental Health Counselor Associate (LMHCA): A prelicensure candidate who has a graduate degree in mental health counseling or related field and is working toward meeting the supervised experience requirements (may renew annually up to six times).

Educational Requirements: LMHC/LMHCA: Master's degree or higher in mental health counseling or related field from a regionally accredited college or university that includes a supervised counseling practicum or internship. Individuals who are certified as NCC or CCMHC are considered to meet educational requirements.

ALL professionals must complete 4 hours of HIV/AIDS education training.

Experiential Requirements: 3 years of full-time counseling or 3,000 hours postgraduate supervised mental health counseling in an approved setting. To include 1,200 hours of direct counseling with individuals, couples, groups, or families and 100 hours of immediate supervision by a board-approved 
supervisor. Graduate from CACREP-accredited programs can count up to 50 hours of supervision and 500 hours of experience from their practicum/ internship.

Exam Required: LMHC: NCE or NCMHCE

LMHCA: None

\section{WEST VIRGINIA}

WV Board of Examiners in Counseling

815 Quarrier St., Suite 212

Charleston, WV 25301

(800) 520-3852

(304) 558-5496 (fax)

counselingboard@msn.com

Roxanne Clay: RCLAY27@msn.com

www.wvbec.org

Title of License: LPC

Provisional Licensed Professional Counselor: An applicant who has met the education and exam requirements, but not the 2 years supervised experience requirement.

Educational Requirements: Master's degree or higher from a program accredited by CACREP or CORE, or a comparable accrediting body, that includes 60 graduate semester hours (or 90 quarter hours) and a practicum and internship. Acceptable graduate degrees include a specialization in community agency counseling, mental health counseling, pastoral counseling, rehabilitation counseling, school counseling, and substance abuse or addictions counseling. Similar degrees that include the word "counseling" and include specific coursework, and are determined by the board by a closely related field, are also acceptable.

Experiential Requirements: Must already possess provisional license. 2 years/ 3,000 hours of post-master's supervised professional counseling experience. If obtained a doctoral degree: 1 year/1,500 hours of postdegree supervised professional counseling experience. At least $50 \%$ of the supervised counseling experience must be in the direct provision of counseling services to clients. A minimum of 1 hour of direct individual supervision is required for every 20 hours of practice. Supervision must be under a board-approved professional.

Exam Required: NCE, CRCE, or NCMHCE 


\section{WISCONSIN}

WI Examining Board of Marriage and Family Therapists, Professional Counselors, and Social Workers

P.O. Box 8935

Madison, WI 53708

(608) 266-2112

(608) 261-7083 (fax)

drl.wi.gov/prof/coun/def.htm

Title of License: LPC

Licensed Professional Counselor Trainee: An applicant who has completed the degree requirements but not the supervised experience; valid for 48 months.

Educational Requirements: Master's degree or higher in professional counseling or equivalent program approved by the board, from a regionally accredited institution that includes a minimum of 42 semester hours (or 63 quarter hours). 3 semester hours of counseling theories and 3 semester hours of a supervised counseling practicum are required.

Experiential Requirements: 2 years/3,000 hours of post-master's supervised professional counseling practice, including 1,000 hours of face-to-face client contact. Supervision must include 1 hour per week of face-to-face supervision and must be provided by a board-approved mental health professional.

Exam Required: NCE, CRCE, or equivalent exam approved by the board, and Wisconsin jurisprudence exam

\section{WYOMING}

WY Mental Health Professions Licensing Board

2001 Capitol Ave., Room 104

Cheyenne, WY 82002

Michelle M. Lamorie, Executive Director: Michelle.lamorie@wyo.gov

(307) 777-7788

(307) $777-3508$ (fax)

plboards.state.wy.us/mentalhealth/index.asp

Title of License: LPC

Provisional Professional Counselor (PPC): An applicant who has received a master's degree, but has not passed the NCE exam or completed the supervised experience requirement; valid for 36 months.

Educational Requirements: Master's degree or higher in counseling, with a minimum of 60 semester hours (or 90 quarter hours) from a CACREP- or 
CORE-accredited program, or a regionally accredited college or university which meets the CACREP criteria for coursework, instructor qualification, and supervision.

Experiential Requirements: 3,000 hours of supervised post-master's clinical experience (1,200 must be direct client contact and 100 hours must be faceto-face supervision). Supervision must be provided by a licensed mental health professional.

Exam Required: NCE, NCMHCE, or CRCE

Acronyms in the list of state licensure requirements refer to the following:

AAODA The Advanced Alcohol and Other Drug Abuse Counselor Examination (administered by the International Certification and Reciprocity Consortium/Alcohol and Other Drug Abuse, Inc.)

ATCB The Art Therapy Credentials Board Certification Examination

CACREP Council for Accreditation of Counseling and Related Educational Programs (an organizational affiliate of ACA that provides professional counselor-training accreditation)

CBMT The Certification Board for Music Therapists Examination

CCMHC Certified Clinical Mental Health Counselor (an NBCC professional counseling specialty title; not a required credential)

CORE Council on Rehabilitation Education (an independent rehabilitation counselor-training accreditation board)

CRC Certified Rehabilitation Counselor (a CRCC professional counseling specialty title; not a required credential)

CRCC Commission on Rehabilitation Counselor Certification (an independent, nongovernmental rehabilitation counselor-credentialing board)

CRCE Certified Rehabilitation Counselor Examination (administered by CRCC for the certification of rehabilitation counselors; also administered by some states for their own credentialing process as an alternative to their clinically oriented exam)

EMAC The Examination for Master Addictions Counselors (administered by NBCC) 
NBCC National Board for Certified Counselors (an independent, nongovernmental professional counselor-credentialing board and an organizational affiliate of ACA)

NCE National Counselor Examination (administered by NBCC for national certification of professional counselors, also used by most states for their own credentialing process)

NCMHCE National Clinical Mental Health Counselor Examination (administered by NBCC for national certification of mental health counselors, also administered by some states for their own licensure process)

PEPK The Practice Examination of Psychological Knowledge (administered by the North American Association of Masters in Psychology)

Exam acronyms listed because of a number of different examinations:

AAODA Advanced Alcohol and Other Drug Abuse Counselor Examination (administered by the International Certification and Reciprocity Consortium/Alcohol and Other Drug Abuse, Inc.)

ATCB Art Therapy Credentials Board Certification Examination

CRCE Certified Rehabilitation Counselor Examination (administered by CRCC for the certification of rehabilitation counselors, also administered by some states for their own credentialing process as an alternative to their clinically oriented exam)

CBMT Certification Board for Music Therapists Examination

EMAC Examination for Master Addiction Counselors (administered by NBCC)

NCE National Counselor Examination (administered by NBCC for national certification of professional counselors; also used by most states for their own credentialing process)

PEPK Practice Examination of Psychological Knowledge (administered by the North American Association of Master in Psychology) 
